University of Nebraska - Lincoln

DigitalCommons@University of Nebraska - Lincoln

\title{
The relationship between subclinical atherosclerosis, non-high- density lipoprotein cholesterol, exercise, and diet among male participants of the PACC Project
}

\author{
Lauren A. Simprini \\ Georgetown University \\ Todd C. Villines \\ Walter Reed Army Medical Center \\ Michael Rich \\ Georgetown University \\ Allen J. Taylor \\ Georgetown University, allen.taylor@medstar.net
}

Follow this and additional works at: https://digitalcommons.unl.edu/usarmyresearch

Simprini, Lauren A.; Villines, Todd C.; Rich, Michael; and Taylor, Allen J., "The relationship between subclinical atherosclerosis, non-high-density lipoprotein cholesterol, exercise, and diet among male participants of the PACC Project" (2012). US Army Research. 225.

https://digitalcommons.unl.edu/usarmyresearch/225

This Article is brought to you for free and open access by the U.S. Department of Defense at DigitalCommons@University of Nebraska - Lincoln. It has been accepted for inclusion in US Army Research by an authorized administrator of DigitalCommons@University of Nebraska - Lincoln. 


\title{
The relationship between subclinical atherosclerosis, non-high-density lipoprotein cholesterol, exercise, and diet among male participants of the PACC Project
}

\author{
Lauren A. Simprini, MD, Todd C. Villines, MD, Michael Rich, MD, Allen J. Taylor, MD*
}

Medstar Health Research Institute, Washington Hospital Center and Georgetown University, Washington, DC, USA (Dr. Simprini); Walter Reed Army Medical Center and Uniformed Services University of the Health Sciences, Washington, DC, USA (Dr. Villines); Georgetown University, Washington, DC, USA (Dr. Rich); and Medstar Health Research Institute, Washington Hospital Center and Georgetown University, Washington, DC, USA (Dr. Taylor)

\section{KEYWORDS:}

Coronary calcium;

Non-HDL;

Exercise;

Diet;

Risk factors
BACKGROUND: Non-high-density lipoprotein (HDL) cholesterol is recommended as a secondary lipid goal treated initially with lifestyle modification. However, the relationship between non-HDL and subclinical atherosclerosis is unknown. We examined the independent relationships between coronary artery calcium (CAC), lipids including non-HDL, exercise, and diet among healthy male participants of the Prospective Army Coronary Calcium (PACC) Project.

METHODS: Male participants from the PACC Project $(n=1637$, mean age 42.8 years; no history of coronary heart disease) were studied. We used validated surveys to measure dietary quality and habitual physical exercise. Fasting lipid concentrations and other cardiovascular risk variables were measured. Subclinical atherosclerosis was detected with the use of electron beam computed tomography for CAC. Factors independently associated with the presence of any detectable CAC (CAC score $>0$ ), including standard CV risk variables, non-HDL, exercise, and diet, were evaluated with the use of logistic regression.

RESULTS: The mean Framingham risk score was $4.6 \pm 2.6 \%$; CAC was present in $22.4 \%$. Fasting lipid concentrations showed mean LDL-C $128 \pm 32 \mathrm{mg} / \mathrm{dL}$, HDL-C $50 \pm 13 \mathrm{mg} / \mathrm{dL}$, TG-C $130 \pm 86$ $\mathrm{mg} / \mathrm{dL}$, and non-HDL-C $154 \pm 37 \mathrm{mg} / \mathrm{dL}$. Men with CAC had significantly greater levels of LDL-C (135 vs $127 \mathrm{mg} / \mathrm{dL}$ ), TG (148 vs $124 \mathrm{mg} / \mathrm{dL}$ ), and non-HDL-C (164 vs $151 \mathrm{mg} / \mathrm{dL}$ ) and less habitual physical activity $(P=0.006)$. There were nonsignificant trends between prevalent CAC, greater amounts of dietary fat intake, and lower HDL-C. In successive multivariable logistic regression models for the dependent variable CAC, only non-HDL-C (odds ratio [OR] 1.012 per $\mathrm{mg} / \mathrm{dL}$; 95\% CI 1.0021.023; $P=.019$ ) and age (OR 1.119 per year; 95\% CI 1.063-1.178; $P<.001$ ) were independently associated with the presence of CAC, and exercise (OR 0.808; 95\% CI $0.703-0.928 ; P=0.003$ ) was associated with the absence of CAC.

CONCLUSIONS: Non-HDL-C and exercise are independently predictive of the presence of subclinical CAC among healthy lower-risk middle-aged men.

(C) 2012 National Lipid Association. All rights reserved.
* Corresponding author.

E-mail address: allen.taylor@medstar.net

Submitted May 13, 2011. Accepted for publication November 23,
Increased levels of non-high density lipoprotein cholesterol (HDL-C) independently predict cardiovascular outcomes. $^{1,2}$ The relationship between non-HDL-C and cardiovascular outcomes suggests that non-HDL-C should 
be related to levels of subclinical atherosclerosis; however, the available data are unclear. Moreover, concordant with recommendations from the National Cholesterol Education Program, which recommends treatment of non-HDL as a secondary lipid goal initially through lifestyle modification, including diet and exercise, ${ }^{3}$ such analyses should be adjusted for lifestyle factors that themselves may be associated with subclinical atherosclerosis. ${ }^{4-7}$ To better understand the relationships between non-HDL-C and subclinical atherosclerosis with the use of coronary artery calcium (CAC) as an early marker of atherosclerotic risk, we examined the independent relationship between CAC and lipids, including non-HDL-C, in addition to exercise and diet among healthy male participants of the Prospective Army Coronary Calcium (PACC) Project.

\section{Methods}

The methods of the PACC project have been previously published. ${ }^{8}$ To summarize briefy, all active-duty Army personnel, ages 40 to 50 years and stationed within the National Capital Area of the Walter Reed Health Care System, were recruited at the time of a periodic, Armymandated physical examination. Individuals with a history of coronary heart disease (CHD), or who indicated a history of angina pectoris by the Rose questionnaire, ${ }^{9}$ were ineligible. Between October 26, 1998 and February 19, 2003, 2259 eligible individuals were screened, and 2000 men and women provided written informed consent to undergo electron beam computed tomography (EBCT) and the cardiovascular risk-screening program. Among enrolled subjects, 1640 were men, of whom 1639 completed the calcium scan and form the basis of this report. Women participants of the PACC Project were not included in this analysis because of their smaller sample size and their low prevalence of CAC.

Each participant provided details of their medical history, lifestyle behaviors, and psychosocial history. Ethnicity was self-reported. Medical history included a history of hypertension, diabetes mellitus, hypercholesterolemia, and current medications. A family history of coronary heart disease included a history of sudden death, myocardial infarction, or coronary revascularization in a relative before the age of 55 (males) or 65 (females). ${ }^{10}$ Family history data were collected separately for first-degree (parents, siblings, children) or second-degree (grandparents, aunts, uncles) relatives.

Resting blood pressure was measured with an automated sphygmomanometer and was recorded as the average of three measurements taken 5 minutes apart with the subject sitting. Hypertension was defined as either a systolic blood pressure of $>135 \mathrm{~mm} \mathrm{Hg}$, a diastolic blood pressure of $>85 \mathrm{~mm} \mathrm{Hg},{ }^{11}$ or a history of hypertension (treated or untreated). Height and weight were measured, and body mass index (BMI) was calculated as weight $/$ height $^{2}\left(\mathrm{~kg} / \mathrm{m}^{2}\right)$. Waist girth was measured as the maximum abdominal circumference between the iliac crest and umbilicus. The metabolic syndrome was classified according to the recommendations of the National Cholesterol Education Program.

Fasting blood was collected for the measurement of total cholesterol, low-density lipoprotein cholesterol (LDL-C), high-density lipoprotein cholesterol (HDL-C), triglyceride cholesterol (TG-C), serum glucose, and hemoglobin A1C. LDL-C was measured with a direct assay and non-HDL-C was calculated as total cholesterol-HDL-C. The predicted 10-year Framingham risk score for incident coronary heart disease was calculated by the use of measured risk factor variables as specified within regression equations from the Framingham Heart Study. ${ }^{12}$

Lifestyle history included tobacco use, dietary intake, and exercise activity. Smoking was self-reported as current, recent (within 6 months) or remote ( $>6$ months) use of any inhaled tobacco products, except for intermittent cigar consumption. A high fat diet was defined as $\geq 48$ on the MEDFICTS dietary questionnaire (added during the course of the study, $(\mathrm{n}=947) .{ }^{13}$ Participants with and without available MEDFICTS dietary questionnaires had similar cardiovascular risk factor levels (data not shown). The Baecke Sports Index was used to evaluate exercise habits ${ }^{14,15}$ on the basis of a previous analysis in which we showed this to be the only component of the habitual physical activity index that correlated with other biometric variables. $^{4}$

EBCT was performed with an Imatron C-150 scanner. Images were obtained with a 40- to 50-slice (3-mm thickness) protocol with image acquisition gated to $60 \%$ to $80 \%$ of the electrocardiographic RR interval while respirations were held. Scans were interpreted in a blinded manner using the Agatston scoring method. ${ }^{16}$ A focus of coronary calcium was defined as the presence of 4 or more contiguous pixels with $>130$ Hounsfield units. A total CAC score was determined from the sum of individual scores of the 4 major epicardial coronary arteries. A scan was considered positive for CAC when the total CAC score was $>0 .{ }^{17,18}$

\section{Statistical analysis}

Risk factor comparisons were performed between patients with and without $\mathrm{CAC}$ by the use of a threshold value of any detectable coronary calcium (CAC score $>0$ ). Continuous variables were expressed as the mean $\pm 1 \mathrm{SD}$ and were compared using a $t$-test for independent groups. Categorical variables were expressed as frequencies and percentages and were compared with the $\chi^{2}$ test or Fisher's exact test where appropriate. Risk variables not showing a normal distribution were log transformed for use in any linear model or hypothesis testing. The relationships between cardiovascular risk variables and CAC were compared with a logistic regression analysis. Risk factor variables with a univariate relationship $(P \leq .20)$ to CAC were entered into the model (block entry). All analyses were performed 
Table 1 Characteristics of the study participants

\begin{tabular}{lc}
\hline Variable & Men $(\mathrm{N}=1639)$ \\
\hline Age, yr, mean $\pm \mathrm{SD}$ & $42.9 \pm 2.7$ \\
White & $76.7 \%$ \\
Black & $19.1 \%$ \\
Hypertension & $30.9 \%$ \\
Family history of CHD & $31.5 \%$ \\
Metabolic syndrome & $6.6 \%$ \\
Current tobacco use & $2.1 \%$ \\
Diabetes mellitus & $1.2 \%$ \\
10-year Framingham risk index CHD & $4.6 \pm 2.6$ \\
Coronary artery calcification score (mean) & $19.4 \pm 110$ \\
Baecke Sports Index & $3.0 \pm 1.0$ \\
Medficts dietary fat index & $52 \pm 28$ \\
Body mass index, kg/m ${ }^{2}$ & $27.8 \pm 3.5$ \\
Waist girth, cm & $95.8 \pm 24.8$ \\
Systolic blood pressure, mm Hg & $124.4 \pm 12.0$ \\
Diastolic blood pressure, mm Hg & $77.6 \pm 8.8$ \\
Total cholesterol, mg/dL & $204.2 \pm 36.2$ \\
LDL cholesterol, mg/dL & $128.5 \pm 31.5$ \\
HDL cholesterol, mg/dL & $50.4 \pm 12.6$ \\
Triglycerides, mg/dL & $129.7 \pm 86.3$ \\
Fasting glucose, mg/dL & $92.7 \pm 11.1$ \\
Hemoglobin A1C, \% $\mathrm{n}=1581$ & $5.4 \pm 0.6$ \\
\hline \multicolumn{1}{c}{ CAC, coronary artery calcium; CHD, coronary heart disease; HDL, } \\
high-density lipoprotein cholesterol; LDL, low-density lipoprotein \\
cholesterol. \\
$\quad$ \\
$\quad$ Mean \pm SD. & \\
The Baecke Sports index score ranges from $1-5$, with 5 being most \\
& \\
active. & \\
& \\
&
\end{tabular}

using SPSS for Windows (v 16; Chicago, IL). A 2-tailed $P$ value of $\mathrm{P}<.05$ was considered significant.

\section{Results}

The demographic and descriptive characteristics of the 1639 participants included in this analysis are shown in Table 1 . The study population was $71.7 \%$ white, $17.9 \%$ black, $6.3 \%$ Hispanic, and $1.5 \%$ were Asian. The mean age was $42.9 \pm 2.7$ years. The most prevalent cardiac risk factors included a family history of CHD in either a first- or second-degree relative (31.9\%) and hypertension $(30.9 \%)$. Current tobacco use was present in $8.5 \%$ of participants, and $6.7 \%$ of participants had the metabolic syndrome. There was a low prevalence of diabetes mellitus (1.2\%). The mean 10-year Framingham risk score for CHD was $4.6 \pm 2.6 \%$, with a range of $0.5 \%$ to $22 \%$. CAC was detected in $22.4 \%$ of participants, with a mean CAC score of $20 \pm 111$. Fasting lipid concentrations revealed mean LDL-C $128 \pm 32 \mathrm{mg} / \mathrm{dL}$, HDL-C $50 \pm 13 \mathrm{mg} / \mathrm{dL}$, TG-C $130 \pm 86 \mathrm{mg} / \mathrm{dL}$, and non-HDL-C $154 \pm 37 \mathrm{mg} / \mathrm{dL}$. The mean final sport index was $3.0 \pm 1.0$ and the mean MEDFICTS score was $52 \pm 28$.

Univariate associations with CAC are shown in Tables 2 and 3. Men with CAC had significantly greater levels of total cholesterol (213 vs 202, $P<.001)$, LDL-C (135 vs 127 $\mathrm{mg} / \mathrm{dL}, P<.001)$, TG (148 vs $124 \mathrm{mg} / \mathrm{dL}, P<.001)$, and non-HDL-C (164 vs $151 \mathrm{mg} / \mathrm{dL}, P<.001)$. The presence of CAC was associated with a trend to lower HDL-C (49 vs 50 $\mathrm{mg} / \mathrm{dL}, P=.06)$. Men with CAC reported less habitual physical activity $(P=.006)$, and a trend to greater dietary fat intake $(P=.12)$. However, among those with a CAC score greater than 0 , the mean non-HDL-C was similar across quartiles of CAC severity.

Univariate comparisons across quartiles of increasing non-HDL-C (Table 4) showed a progressively greater proportion of subjects with prevalent coronary calcium and concomitantly with lower levels of physical activity (Fig. 1). No statistical interaction for non-HDL and physical activity was identified within the association of these variables with CAC. Individuals with high levels of nonHDL also were more likely to have hypertension, a higher Framingham risk score, greater body mass index, and prevalent metabolic syndrome.

In a series of multivariable logistic regression models evaluating the independent relationships of cardiovascular risk variables with CAC (dependent variable), significant associations were found for non-HDL-C (odds ratio [OR] 1.012 per $\mathrm{mg} / \mathrm{dL} ; 95 \%$ confidence interval [95\% CI] $1.002-$ $1.023 ; P=.019)$ and age (OR 1.119 per year; 95\% CI $1.063-1.178 ; P<.001)$. Serum concentrations of LDL-C and HDL-C were not found to be significant after adjusting for age and the full lipid profile. Exercise (OR 0.808; 95\% CI 0.703-0.928; $P=.003$ ) was associated with the absence of CAC. A diet high in saturated fat was not independently associated with CAC.

Table 2 Relationship between CAC and demographic cardiovascular risk factors

\begin{tabular}{|c|c|c|c|c|c|}
\hline \multirow[b]{3}{*}{ Positive variable } & \multicolumn{4}{|c|}{ EBCT results } & \multirow[b]{3}{*}{$P$ value } \\
\hline & \multicolumn{2}{|c|}{ CAC positive $n=367$} & \multicolumn{2}{|c|}{ CAC negative $n=1272$} & \\
\hline & $\mathrm{N}$ & $\%$ & $n$ & $\%$ & \\
\hline African-American race & 52 & 13.4 & 353 & 21.9 & $<.001$ \\
\hline Hypertension & 147 & 37.9 & 429 & 26.6 & $<.001$ \\
\hline Current smoker & 32 & 8.2 & 121 & 7.5 & .62 \\
\hline Diabetes mellitus & 3 & 0.8 & 17 & 1.1 & .62 \\
\hline Family history of CHD & 94 & 24.5 & 283 & 17.7 & .002 \\
\hline Metabolic syndrome & 98 & 25.3 & 289 & 17.9 & .001 \\
\hline
\end{tabular}

CAC, coronary artery calcium; CHD, coronary heart disease; EBCT, electron beam computed tomography. 
Table 3 Relationships between CAC, lipid concentrations, diet, and exercise

\begin{tabular}{lccc}
\hline & EBCT results & & \\
\cline { 2 - 3 } Variable & CAC positive, $\mathrm{n}=367$ & CAC negative, $\mathrm{n}=1272$ & $<3.6 \pm 2.9$ \\
\hline Age, $\mathrm{yr}$ & $42.7 \pm 2.6$ & $202 \pm 36$ & $<.001$ \\
Total cholesterol, $\mathrm{mg} / \mathrm{dL}$ & $213 \pm 38$ & $127 \pm 31$ & $<.001$ \\
$\mathrm{LDL}$ cholesterol, $\mathrm{mg} / \mathrm{dL}$ & $135 \pm 32$ & $51 \pm 13$ & $<.001$ \\
$\mathrm{HDL}$ cholesterol, $\mathrm{mg} / \mathrm{dL}$ & $49 \pm 11$ & $124 \pm 80$ & .06 \\
Triglycerides, $\mathrm{mg} / \mathrm{dL}$ & $148 \pm 103$ & $151 \pm 36$ & $<.001$ \\
Non-HDL-C, $\mathrm{mg} / \mathrm{dL}$ & $164 \pm 38$ & $52.8 \pm 29$ & $<.001$ \\
Final MEDFICTS score & $49.4 \pm 28$ & $3.1 \pm 1$ & .12 \\
Baecke Sport Index & $2.9 \pm 1.1$ & .006 \\
\hline
\end{tabular}

CAC, coronary artery calcium; EBCT, electron beam computed tomography; HDL, high-density lipoprotein cholesterol; LDL, low-density lipoprotein cholesterol.

Mean \pm SD.

\section{Discussion}

We examined the relationship between subclinical atherosclerosis in middle-aged men and non-HDL-C as a factor which predisposes individuals to heighted CHD risk. We found a significant association between serum concentrations of non-HDL-C and the incidence of coronary artery calcium. This association remained evident after controlling for LDL-C and HDL-C, in addition to other cardiovascular risk variables and behavioral variables such as exercise and dietary fat intake. These data support guideline recommendations on non-HDL-C cholesterol as a secondary target of lipid lowering therapy.

The authors of several previous studies have suggested an association between non-HDL cholesterol and subclinical atherosclerosis. Orakzai et $\mathrm{al}^{19}$ studied men and women with a mean age of 53 years and showed univariate relationships between $\mathrm{CAC}$ and lipid variables including LDL-C, HDL-C, and non-HDL-C. However, similar to our study, only non-HDL-C was independently related to CAC. Simon et $\mathrm{al}^{7}$ studied asymptomatic men and compared the associations of extracoronary plaque or a CAC score above 100 with lipid levels showing a stronger relationship between atherosclerosis and non-HDL-C than LDL-C. In contrast, a study by Allison et $\mathrm{al}^{20}$ failed to find an independent relationship between extracoronary and coronary calcium and non-HDL-C after adjustment for cardiovascular risk factors. However, these studies generally controlled for standard cardiovascular risk factors in evaluating non-HDL-C, whereas diet and exercise variables modify non-HDL-C levels and subclinical atherosclerosis.

Table 4 Demographic and cardiovascular risk variables across quartiles of increasing Non-HDL cholesterol $(\mathrm{N}=1640)$

\begin{tabular}{|c|c|c|c|c|c|}
\hline & $\begin{array}{l}\mathrm{Q1} \\
\mathrm{N}=421\end{array}$ & $\begin{array}{l}\mathrm{Q} 2 \\
\mathrm{~N}=408\end{array}$ & $\begin{array}{l}\mathrm{Q3} \\
\mathrm{N}=403\end{array}$ & $\begin{array}{l}\text { Q4 } \\
N=408\end{array}$ & $P$ value \\
\hline Age & $42.8 \pm 2.7$ & $42.8 \pm 2.7$ & $43.0 \pm 2.6$ & $42.9 \pm 2.8$ & 0.43 \\
\hline Body mass index $\left(\mathrm{kg} / \mathrm{m}^{2}\right)$ & $26.8 \pm 3.0$ & $27.4 \pm 3.1$ & $28.0 \pm 3.0$ & $28.9 \pm 4.4$ & $<0.001$ \\
\hline Systolic blood pressure (mm Hg) & $122.9 \pm 12.1$ & $123.9 \pm 12.4$ & $125.1 \pm 11.6$ & $125.6 \pm 11.5$ & 0.01 \\
\hline Diastolic blood pressure (mm Hg) & $75.7 \pm 9.0$ & $77.5 \pm 10.0$ & $78.1 \pm 8.0$ & $79.1 \pm 8.9$ & $<0.001$ \\
\hline Waist girth $(\mathrm{cm})$ & $93.4 \pm 37.5$ & $95.9 \pm 31.3$ & $96.0 \pm 8.6$ & $97.8 \pm 7.6$ & 0.12 \\
\hline $\mathrm{HDL}-\mathrm{C}(\mathrm{mg} / \mathrm{dL})$ & $54.7 \pm 14.2$ & $51.2 \pm 12.1$ & $48.5 \pm 11.6$ & $46.8 \pm 11.0$ & $<0.001$ \\
\hline Blood glucose $(\mathrm{mg} / \mathrm{dL})$ & $90.5 \pm 8.9$ & $92.0 \pm 11.6$ & $93.2 \pm 10.3$ & $95.1 \pm 13.3$ & $<0.001$ \\
\hline Framingham risk score (10 year CHD) & $2.6 \pm 1.4$ & $3.9 \pm 1.8$ & $5.1 \pm 2.3$ & $6.8 \pm 2.8$ & $<0.001$ \\
\hline Diabetes mellitus & $1(0.2 \%)$ & $6(1.5 \%)$ & $5(1.2 \%)$ & $7(1.7 \%)$ & 0.20 \\
\hline Hypertension & $97(23.0 \%)$ & $126(30.9 \%)$ & $136(33.7 \%)$ & $148(36.3 \%)$ & $<0.001$ \\
\hline Family history of premature CHD* & $113(26.8 \%)$ & $131(32.1 \%)$ & $138(34.2 \%)$ & $137(33.6 \%)$ & 0.08 \\
\hline African American race & $82(19.5 \%)$ & $74(18.2 \%)$ & $73(18.1 \%)$ & $65(15.9 \%)$ & 0.85 \\
\hline Metabolic syndrome & $10(2.4 \%)$ & $22(5.5 \%)$ & $34(8.5 \%)$ & $43(10.6 \%)$ & $<0.001$ \\
\hline Current smoking & $10(2.4 \%)$ & $10(2.6 \%)$ & $5(1.2 \%)$ & $10(2.5 \%)$ & 0.20 \\
\hline Statin use & $16(3.8 \%)$ & $32(7.8 \%)$ & $22(5.5 \%)$ & $24(5.9 \%)$ & 0.10 \\
\hline Coronary calcium score $>0$ & $66(15.7 \%)$ & $82(21.1 \%)$ & $98(24.3 \%)$ & $121(29.7 \%)$ & $<0.001$ \\
\hline Baecke Sport Index & $3.2 \pm 1.0$ & $3.0 \pm 1.0$ & $3.0 \pm 1.0$ & $2.9 \pm 1.0$ & 0.002 \\
\hline MEDFICTS score ${ }^{* *}$ & $49.9 \pm 28.0$ & $52.1 \pm 28.7$ & $50.9 \pm 26.7$ & $53.6 \pm 29.3$ & 0.54 \\
\hline
\end{tabular}

CHD, coronary heart disease.

*Premature CHD either first or second degree relatives.

**Number of subjects total for MEDFICTS $=947$. 


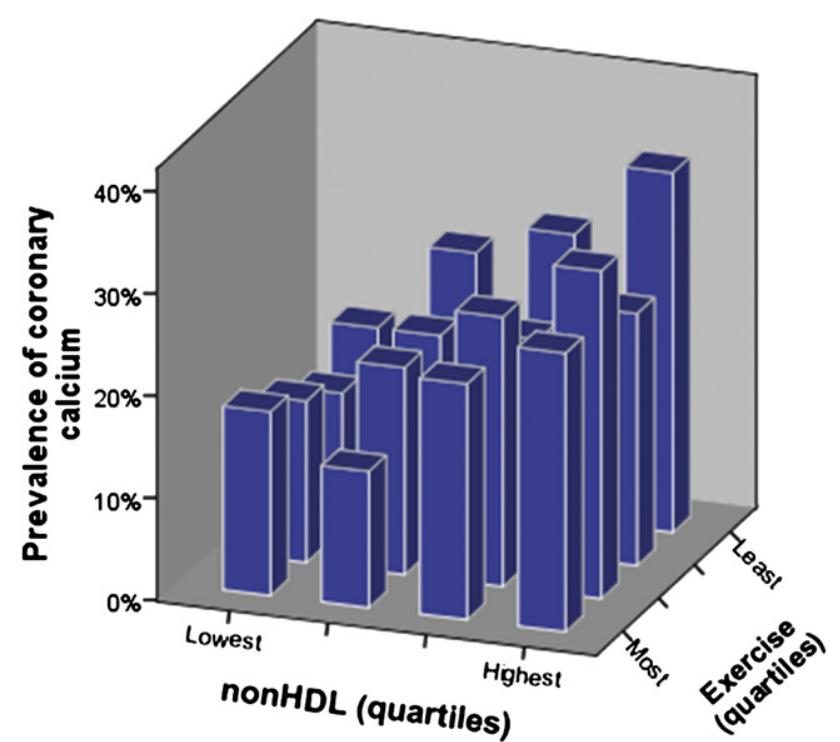

Figure 1 Prevalence of CAC among quartiles of non-HDL-C and exercise as measured by the Baecke sports index.

Our study extends these previous studies by showing that, among lipid concentrations associated with cardiovascular risk, non-HDL-C, rather than LDL-C or HDL-C, was associated with CAC among multivariable models controlling for measured cardiovascular risk variables and behavioral variables. Although our study cannot be used to infer causality, non-HDL-C provides a measure of the concentration of the spectrum of atherogenic plasma lipoproteins containing apolipoprotein B, including LDL, IDL, lipoprotein(a), TG-rich remnants of VLDL, and chylomicrons. Guideline recommendations for the treatment of non-HDL cholesterol include therapeutic lifestyle changes, such as exercise and diet, when triglyceride concentrations are increased $(>200 \mathrm{mg} / \mathrm{dL})$. Thus, our study could suggest an opportunity to more broadly and primarily target non-HDL cholesterol as a component of lifetime cardiovascular risk, even among those without overt hypertriglyceridemia as a strategy to reduce the incidence and burden of coronary atherosclerosis.

We found that adjustment for diet and exercise attenuated but did not negate the associations of non-HDL-C with $\mathrm{CAC}$ and that exercise was associated with a lower prevalence of CAC. Studies have shown inconsistent findings between CAC and physical activity. In the MultiEthnic Study of Atherosclerosis (ie, MESA) study, a crosssectional analysis suggested that weekly levels of physical activity were not independently associated with the presence of subclinical atherosclerosis. ${ }^{21}$ However, in a longitudinal study within the CARDIA cohort, cardiorespiratory fitness as measured by symptom-limited exercise treadmill test was associated with a reduced prevalence of CAC after 15 years. Findings from the MESA study also suggest that dietary quality, assessed by inflammatory markers, was associated with CAC. Our study examined dietary quality using a survey instrument designed to identify compliance with the American Heart Association recommendations for dietary fat intake. ${ }^{6}$ Although total fat and saturated fat dietary intake are important components of a heart healthy diet, this score does not evaluate other aspects of dietary intake that may contribute to cardiovascular risk factors, such as total caloric intake.

Our study has limitations, including that this analysis included only men because of the limited sample of women enrolled in the PACC Project. In addition, our findings of an association between non-HDL and CAC, while plausible in the context of previous studies and the biologic relationship between apolipoprotein B particles and atherosclerosis, cannot be construed as creating a causal linkage. Finally, more data on the graded relationship between CAC severity and non-HDL-C would enhance our understanding of the relationships described in our study.

In conclusion, among asymptomatic low-risk, middleaged men, non-HDL-C and exercise independently predict the presence of CAC. Targeting non-HDL cholesterol even at lower triglyceride concentrations deserves further study as a method to treat atherosclerosis and its attendant cardiovascular risk.

\section{Acknowledgments}

The opinions or assertions herein are the private views of the authors and are not to be construed as reflecting the views of the Department of the Army or the Department of Defense.

\section{Financial disclosure}

Supported by the Congressionally-directed, Peer Reviewed Medical Research Program, grant number ERMS 00239017-00216.

\section{References}

1. Robinson JG, Wang S, Smith BJ, Jacobson TA. Meta-analysis of the relationship between non-high-density lipoprotein cholesterol reduction and coronary heart disease risk. J Am Coll Cardiol. 2009;53: 316-322.

2. Sniderman AD, Williams K, Contois JH, et al. A Meta-Analysis of Low-Density Lipoprotein Cholesterol, Non-High-Density Lipoprotein Cholesterol, and Apolipoprotein B as Markers of Cardiovascular Risk. Circ Cardiovasc Qual Outcomes. 2011;4:337-345.

3. Executive Summary of The Third Report of The National Cholesterol Education Program (NCEP) Expert Panel on Detection, Evaluation, And Treatment of High Blood Cholesterol In Adults (Adult Treatment Panel III). JAMA. 2001;285:2486-2497.

4. Taylor AJ, Watkins T, Bell D, et al. Physical activity promotes a healthy cardiovascular risk factor profile but is unrelated to the presence or extent of subclinical atherosclerosis. Med Sci Sports Exerc. 2002;34:228-233.

5. Lee CD, Jacobs DR Jr., Hankinson A, Iribarren C, Sidney S. Cardiorespiratory fitness and coronary artery calcification in young adults: The CARDIA Study. Atherosclerosis. 2009;203:263-268.

6. Nettleton JA, Steffen LM, Schulze MB, et al. Associations between markers of subclinical atherosclerosis and dietary patterns derived by principal components analysis and reduced rank regression in the 
Multi-Ethnic Study of Atherosclerosis (MESA). Am J Clin Nutr. 2007; 85:1615-1625.

7. Simon A, Chironi G, Gariepy J, Del PM, Levenson J. Differences between markers of atherogenic lipoproteins in predicting high cardiovascular risk and subclinical atherosclerosis in asymptomatic men. Atherosclerosis. 2005;179:339-344.

8. O'Malley PG, Taylor AJ, Gibbons RV, et al. Rationale and design of the Prospective Army Coronary Calcium (PACC) Study: utility of electron beam computed tomography as a screening test for coronary artery disease and as an intervention for risk factor modification among young, asymptomatic, active-duty United States Army Personnel. Am Heart J. 1999;137:932-941.

9. Rose G, McCartney P, Reid DD. Self-administration of a questionnaire on chest pain and intermittent claudication. Br J Prev Soc Med. 1977; 31:42-48.

10. Executive Summary of The Third Report of The National Cholesterol Education Program (NCEP) Expert Panel on Detection, Evaluation, And Treatment of High Blood Cholesterol In Adults (Adult Treatment Panel III). JAMA. 2001;285:2486-2497.

11. The sixth report of the Joint National Committee on prevention, detection, evaluation, and treatment of high blood pressure [see comments] [published erratum appears in Arch Intern Med 1998 Mar 23;158(6): 573]. Arch Intern Med. 1997;157:2413-2446.

12. Anderson KM, Odell PM, Wilson PW, Kannel WB. Cardiovascular disease risk profiles. Am Heart J. 1991;121:293-298.

13. Taylor AJ, Wong H, Wish K, et al. Validation of the MEDFICTS dietary questionnaire: A clinical tool to assess adherence to American Heart Association dietary fat intake guidelines. Nutr J. 2003;2:4.
14. Baecke JA, Burema J, Frijters JE. A short questionnaire for the measurement of habitual physical activity in epidemiological studies. Am J Clin Nutr. 1982;36:936-942.

15. Kondos GT, Hoff JA, Sevrukov A, et al. Electron-beam tomography coronary artery calcium and cardiac events: a 37-month follow-up of 5635 initially asymptomatic low- to intermediate-risk adults. Circulation. 2003;107:2571-2576.

16. Agatston AS, Janowitz WR, Hildner FJ, Zusmer NR, Viamonte MJ, Detrano R. Quantification of coronary artery calcium using ultrafast computed tomography. J Am Coll Cardiol. 1990;15:827-832.

17. Mahoney LT, Burns TL, Stanford W, et al. Coronary risk factors measured in childhood and young adult life are associated with coronary artery calcification in young adults: the Muscatine Study. J Am Coll Cardiol. 1996;27:277-284.

18. Taylor AJ, Feuerstein IM, Wong H, Barko W, Brazaitis M, O'Malley PG. Do conventional risk factors predict subclinical coronary artery disease? Results from the Prospective Army Coronary Calcium Project. Am Heart J. 2001;141:463-468.

19. Orakzai SH, Nasir K, Blaha M, Blumenthal RS, Raggi P. Non-HDL cholesterol is strongly associated with coronary artery calcification in asymptomatic individuals. Atherosclerosis. 2009;202:289-295.

20. Allison MA, Pavlinac P, Wright CM. The differential associations between HDL, non-HDL and total cholesterols and atherosclerotic calcium deposits in multiple vascular beds. Atherosclerosis. 2007;194: e87-e94.

21. Bertoni AG, Wong ND, Shea $S$, et al. Insulin resistance, metabolic syndrome, and subclinical atherosclerosis: the Multi-Ethnic Study of Atherosclerosis (MESA). Diabetes Care. 2007;30:2951-2956. 